\title{
Critical Designing and Flow Analysis of Various Nozzles using CFD Analysis
}

\author{
Prapti Joshi ${ }^{1}$, Tarun Gandhi ${ }^{2}$, Sabiha Parveen ${ }^{3}$ \\ Dept of Aerospace Engg \\ Chandigarh University Gharuan, \\ Mohali-140413
}

\begin{abstract}
Nozzle component of a rocket has been under constant development and research for better efficiency and performance. A nozzle is basically a 2-D pipe visualized in 3$D$ with varying cross- sectional area used to direct and accelerate the flow of gases produced by the combustion chamber. This research includes study of design of several nozzles and comparing them with the existing ones as in the advancing years various organizations are planning to explore other planets for research purposes to study their habitat and to find a better home. There would be difficulty in operating nozzles where the atmosphere is different than on Earth. There are many crucial planets where the atmosphere consists of many other gases like hydrogen, helium, methane and carbon dioxide where the nozzle efficiency must be maintained. So, the present study incorporates various parameters such as Mach velocity, temperature and pressure. A series of CFD simulations are carried out to understand the nozzle efficiency at different conditions of temperature by critical analysis of nozzles in ANSYS Fluent and designing in Catia V5.
\end{abstract}

Keywords: Nozzles, Nozzle Efficiency, ANSYS, Mach Velocity, Temperature, Altitudes, Working Fluids

\section{INTRODUCTION}

A nozzle is basically an isentropic device where there is zero change in entropy and the fluid flowing in the nozzle has an adiabatic and steady flow i.e. it does not impart any heat to the surrounding walls. As the fluid flows from the inlet to the exit its velocity at the end increases with decrease in parameters like pressure and density. Nozzle is used to accelerate the flow of gases and produce a jet of stream with high velocity in the expense of enthalpy drop. The hot pressurized gases, passing through the nozzle is converted to a supersonic speed due to the conversion of heat energy into kinetic energy [1]. The primary function of exhaust nozzles is efficient conversion of potential energy of the exhausting gas to kinetic energy by increasing the exhaust velocity, which is accomplished through efficiently expanding the exhausting gases to the ambient pressure [1]. The pressure ratio across the nozzle controls the expansion process and the maximum uninstalled thrust for a given engine is obtained when the exit pressure $\left(p_{e}\right)$ equals the ambient pressure $\left(p_{0}\right)$ [2]. A rocket nozzle can be visualized as a $3 \mathrm{~d}$ pipe with variable cross-sectional area. For huge values of thrust, the active vitality of the fluid must be high that require high speed fumes [3]. For designing a perfect nozzle, the area ratio must be kept in mind. The area ratio is optimized to provide the maximum performance during a critical time of the engine operating period [4].

The nozzle works on the Bernoulli's principle and Newton's third law of motion. Bernoulli's principle states that as the speed of a moving fluid increases, the pressure within the fluid decreases that explains the reason behind the increase in velocity and drop in pressure value of the fluid at the outlet. The third law of motion in turn explains that the amount of thrust produced in the engine depends on the mass flow rate exiting through the nozzle and the exit pressure. This is the main reason for the research and advancement in the rocket nozzle these days aiming towards the improvement of the rocket design that allows increase in the mass flow rate thereby increasing the thrust.

\section{TYPES OF NOZZLES}

\section{Convergent nozzle:}

When the cross-sectional area of the nozzle decreases continuously from entrance to exit the nozzle hence formed is known as a convergent nozzle. This nozzle is essential when the critical pressure ratio of the rocket is equal to or less than the back pressure (the pressure that opposes the fluid flow inside the nozzle). The fluid in a convergent nozzle gains kinetic energy and flows from the inlet towards the exit at high velocity.

\section{Divergent nozzle:}

In a divergent nozzle the area increases continuously from entrance to the exit. This is essential when back pressure is less than the critical pressure ratio. To get the maximum benefit of a divergent nozzle at least $20 \%$ of the fluid should pass through the center.

\section{Convergent-Divergent nozzle:}

In a cd nozzle the area where the convergent section and the divergent section meets is known as throat of the nozzle. C-d nozzles are used by the rocket engines with a comparably high area ratio to maximize thrust and exhaust velocity so that high pressure ratios are employed [2].

\section{Bell nozzle:}

It is most commonly used in rocket engines as it provides greater exit mass flow rate. Bell shaped nozzle are also 
known as contour nozzle as they have a deflection angle behind the throat. The momentum provided by bell nozzles is axial that assists in providing high values of thrust at all altitudes. The reason for the large expansion angle in these nozzles is to give rise to expansion shock waves. There is a reversal in the slope to generate compression shock waves. As a result, two set of shock waves are formed that coincide and cancel each other at the exit, hence maximizing the efficiency.

\section{RELATED WORK}

Many researchers are researching in this topic and have worked on different techniques to obtain various results. There are a lot of designs related to nozzles and they are being used for many years. Ever since the jet and rocket propulsion systems have come out to the surface, researchers have invented and used many types of nozzles, mainly to increase the thrust of nozzles in off design working conditions. Among these various designs, features of the aerospike nozzle have attracted researchers since mid-1950s [5]. Many theoretical studies of the aerospike nozzle have been carried out in the 1960s.

Y.M. Akib [6] discussed dual-bell nozzles, i.e. a dualbell nozzle has an inner base nozzle contour, a wall inflection, and an outer extension nozzle contour shown in fig. 1 below. A bell nozzle is designed in such a way that it accelerates the flow to result in uniform, parallel and wave-free supersonic flow. According to B. D. Baloni [1], An improper contour in the design of bell-shaped nozzles will result in the presence of weak waves, which may coalesce to form a finite shock and prevent a uniform flow in the test section.

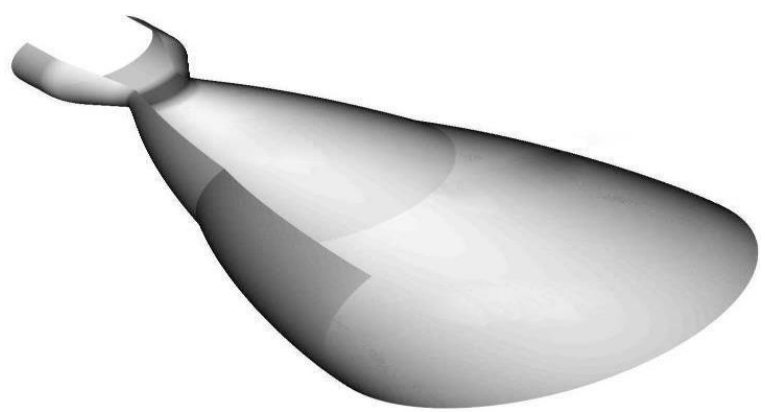

Fig. 1 Dual bell nozzle

\section{METHODOLOGY}

Following methodology used to do the nozzles designing and its analysis which is elaborated below

\section{A. DESIGNING THE NOZZLE}

The designing of the nozzle was done using CATIA V5 and ANSYS design modeler. 2d model was constructed as shown in Fig.2 (a) for $2 d$ bell nozzle and (b) for $2 \mathrm{~d}$ conical nozzle.
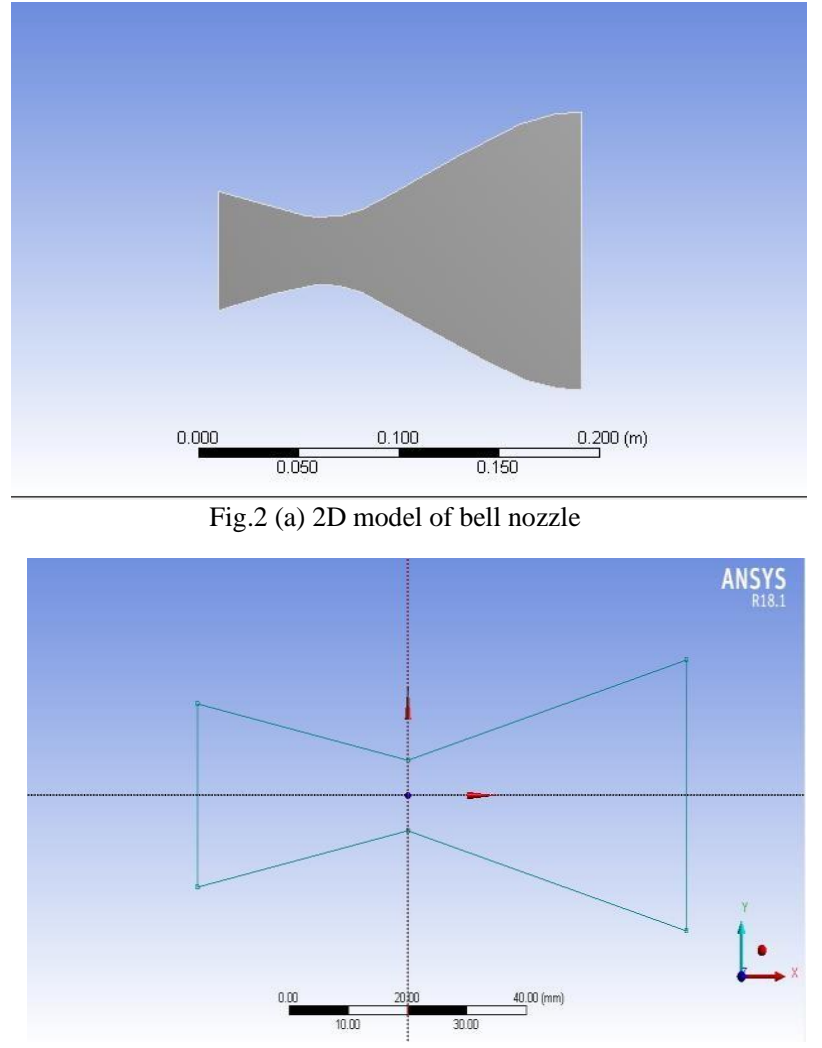

Fig.2 (b) 2D model of conical nozzle

\section{B. MESHING}

Meshing was generated through automatic mapped body meshing with face sizing, refinement and edge sizing of element 5 as shown in Fig.3.

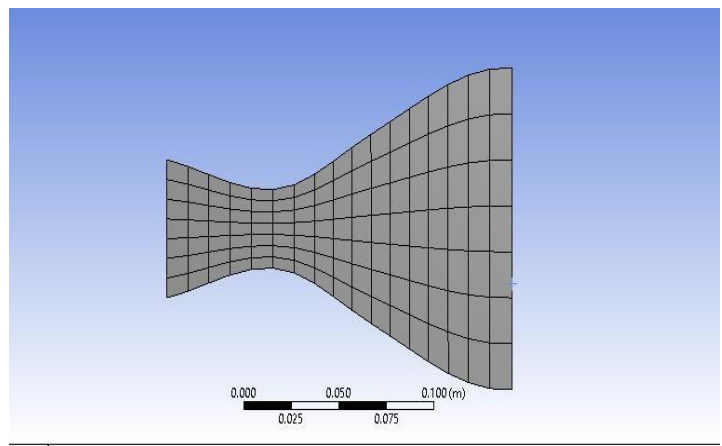

Fig.3 (a) Meshing of bell nozzle

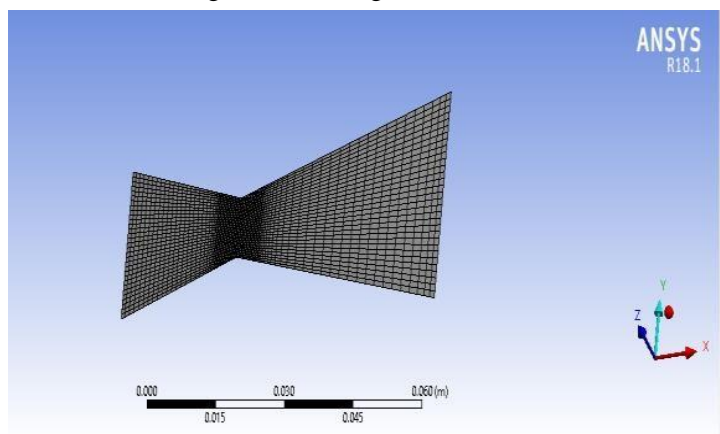

Fig.3 (b) Meshing of conical nozzle 
Boundary conditions for the nozzles while being tested in ANSYS Fluent 18.1 are given in Table. 1.

Table.1 BOUNDARY CONDITIONS [3]

\begin{tabular}{|c|c|c|}
\hline S.No & Location & Value \\
\hline 1 & Inlet pressure & $3 \times 10^{5} \mathrm{~Pa}$ \\
\hline 2 & Outlet pressure & 0 \\
\hline 3 & Wall condition & No slip \\
\hline
\end{tabular}

Material properties for the working fluid are given in Table. 2. Analysis of designs are done perfectly in ANSYS Fluent and is ensured that the results are accurate, and the graphs made are properly understandable.

Table.2 MATERIAL PROPERTIES [3]

\begin{tabular}{|c|c|c|}
\hline S.No & Properties & Value \\
\hline 1 & Density & Ideal gas \\
\hline 2 & Viscosity & Sutherland \\
\hline 3 & Specific heat & $1006.43 \mathrm{~J} / \mathrm{Kg} \mathrm{K}$ \\
\hline
\end{tabular}

\section{RESULTS AND DISCUSSIONS}

The two main types of nozzles present in the industry are traditional conical CD nozzle and bell- shaped nozzle. Analysis and comparison of both is done below and results are shared for better understanding their nature and their own characteristics that they offer.

\section{SIMULATION OF CONICAL SHAPED NOZZLE}

All the components of velocity i.e. $\mathrm{x}, \mathrm{y}$ and $\mathrm{z}$ and energy as well as conductivity shows the same trend in graph as decreasing linearly with increase in iterations in conical nozzle. Value of epsilon first decreased and then attained the peak value and then again become constant.

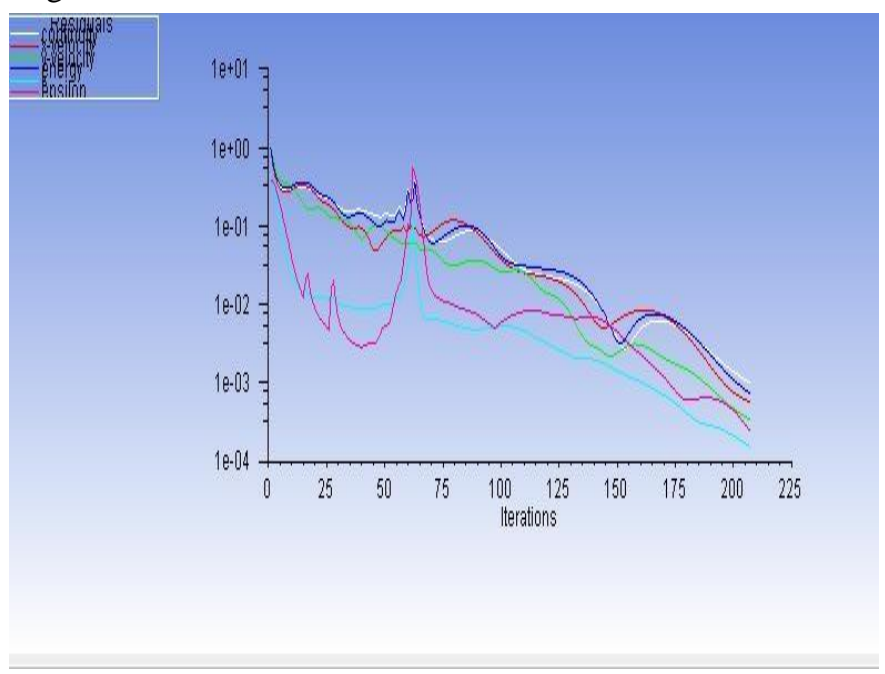

Fig.4 Scaled Iterations for conical nozzles

\section{Case I. Pressure Flow Visualization}

Pressure in conical nozzle case is $7.15 \times 10^{3} \mathrm{~Pa}$ at the inlet area and then it increased to get to a value of $7.41 \times 10^{4} \mathrm{~Pa}$ at throat and then become constant at outlet having final value of $9.08 \times 10^{4} \mathrm{~Pa}$ shown in fig 4.1 below.

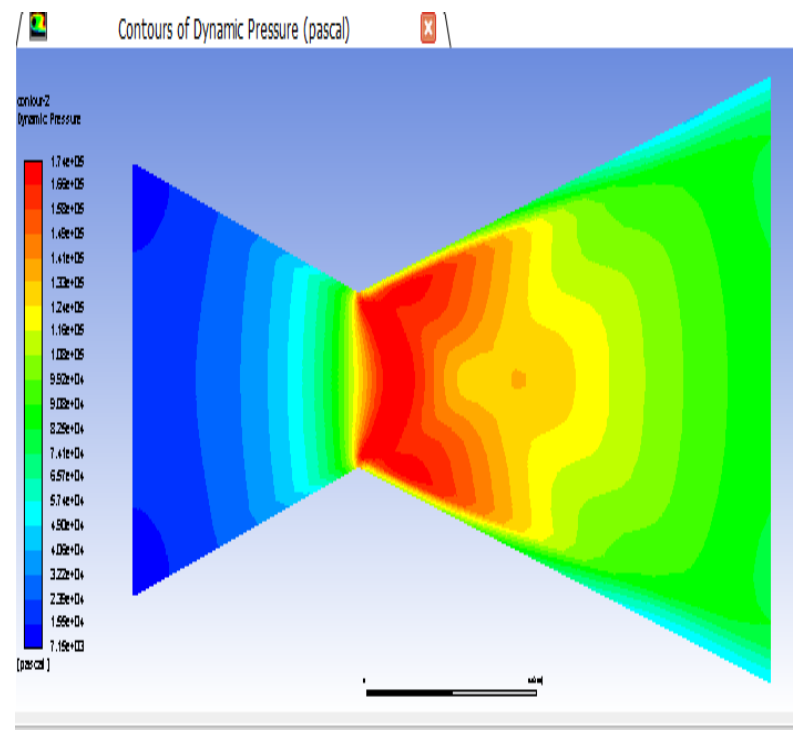

Fig.4.1 Pressure contours over conical nozzle

Static pressure is the pressure measured when the fluid is at rest. From the above figures, it can be observed that, the pressure is maximum at the convergent section of the C-D nozzle with a value of $7.13 \times 10^{3} \mathrm{~Pa}$. While at the throat, it increases and varies with $7.41 \times 10^{4} \mathrm{~Pa}$. However, at the divergent section, the decreases linearly to a value of $9.26 \times 10^{4} \mathrm{~Pa}$. Results can be seen in Fig. 4.1 above.

\section{Case II. Mach Number Visualization}

Mach velocity is the ratio of the speed of object with the speed of air. When the value is $(M<1)$, the flow is subsonic. When it reaches at $(M=1)$, flow is sonic and when the $M$ rises further than that $(M>1)$, then that is called supersonic. Rocket nozzles operate mainly at supersonic conditions.

1. Conditions for Simulation of Conical Nozzle At inlet, the value of Mach is $1.61 \times 10^{-1}$ and then it increased to a value of $8.23 \times 10^{-1}$ and further increased to a final value of 2.81 i.e. Supersonic flow.

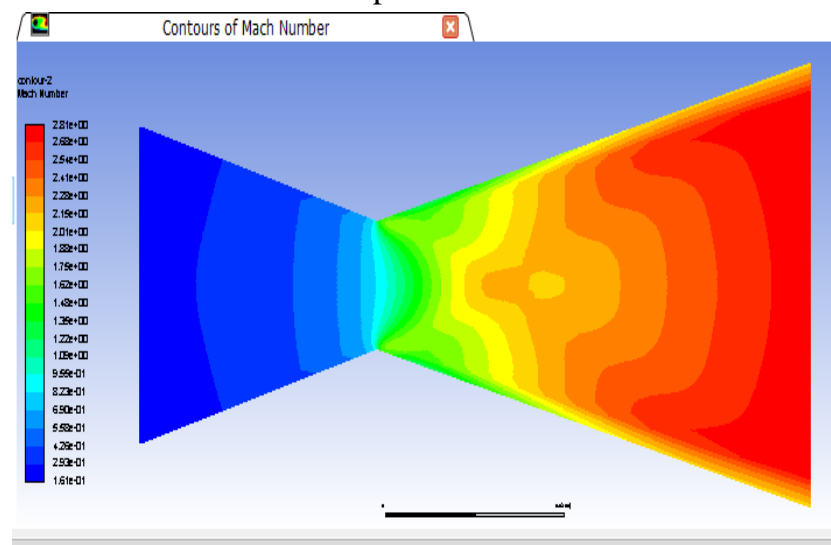

Fig. 4.3 Mach no. variation over conical nozzle 


\section{SIMULATION OF BELL NOZZLE}

All the values i.e. $\mathrm{x}, \mathrm{y}, \mathrm{z}$ velocity; energy; epsilon showed a linear graph with constant values with increasing iterations.

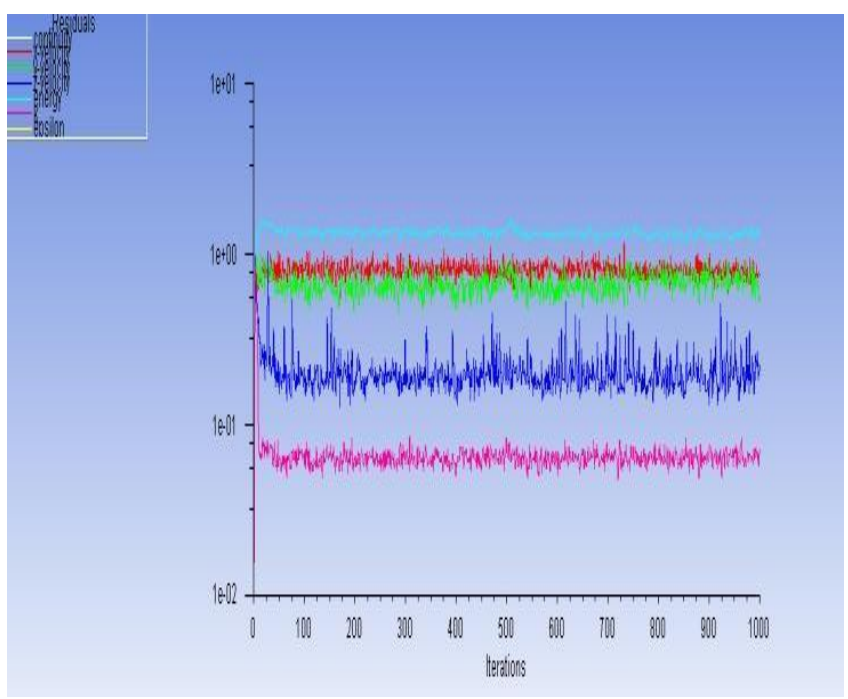

Fig.5 Iterations of bell nozzle

\section{Case III. Pressure Contour Over Bell nozzle}

Pressure in bell shaped nozzle in Fig 5.1 which is remained constant throughout the nozzle at $5.415 \times 10^{004} \mathrm{~Pa}$ with just a slight increase at the throat of the nozzle attaining $1.680 \times 10^{006} \mathrm{~Pa}$.

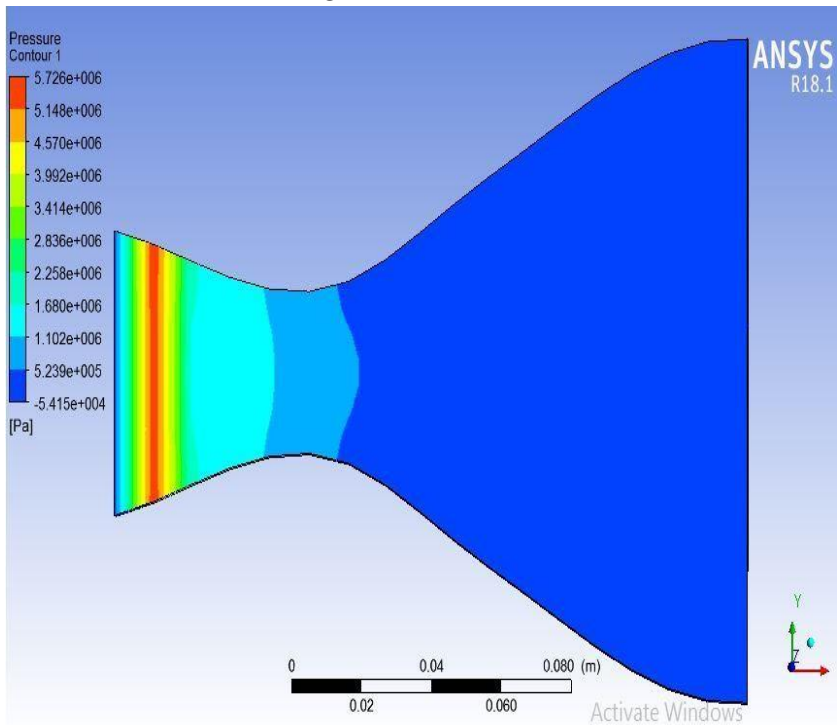

Fig.5.1 Pressure contours over bell nozzle

\section{Case IV. Velocity distribution over bell nozzle}

Velocity contours showed a rapid increase in the values from $5.337 \times 10^{2}$ at inlet to a value of $1.334 \times 10^{3}$ at the exit of the nozzle shown in fig 5.2.

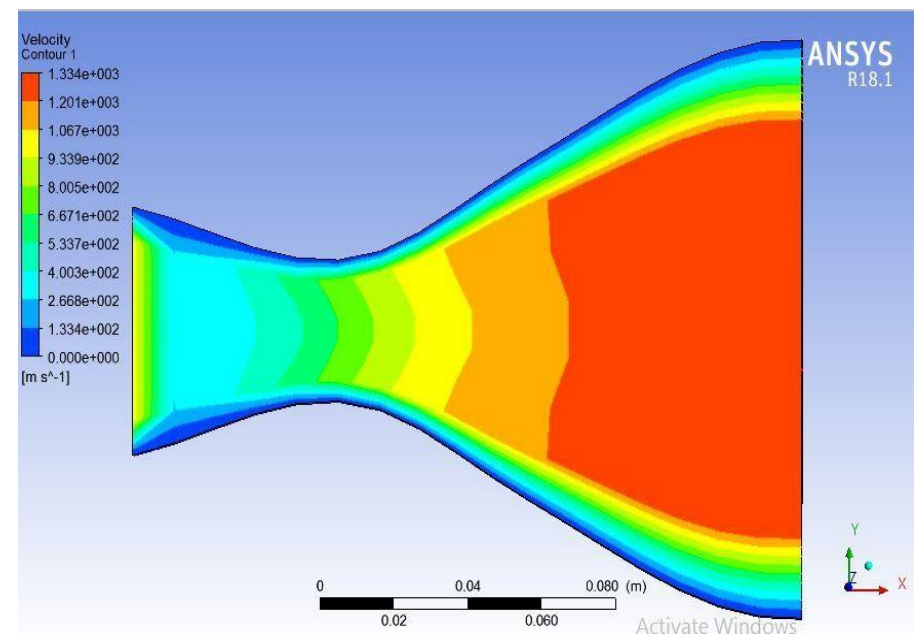

Fig. 5.2 Velocity distribution over bell nozzle

Result: Thus, it is seen that the contours of bell nozzle offer far better pressure and velocity curves than the contours of conical nozzle.

\section{REFRENCES}

1. Beena D. Baloni, Sonu P. Kumar, S. A. Channiwala, "Computational Analysis of Bell Nozzles", Proceedings of the $4^{\text {th }}$ International Conference of Fluid Flow, Heat and Mass Transfer (FFHMT'17).

2. Gandikota Babu Vishnu Kishore, Kaparthy Akash, "CFD Analysis of a Rocket Nozzle with one Inlet at Mach 0.6."

3. Mohammad Arif Hussain, M.Satya Prasad, Dr. S.Nagakalyan, "Design And Flow Analysis Of Various Convergent - Divergent Nozzles By Using Computational Fluid Dynamics (Cfd)", IJIRAE/RS/Vol.06/Issue05/MYAE10087.

4. George P.Sutton ,Oscar Biblarz, "Rocket propulsion elements", seventh edition, Wiley and sons, page no. 22.

5. Hearth, D. P. and G. C. Gorton, "Investigation of Thrust and Drag Characteristics of a Plug-Type Exhaust Nozzle", NACA RM E53L16, 1954.

6. Yeasir Mohammad Akib, Asif Kabir, and Mahdi Hasan, "Critical Assessment of Altitude Adaptive Dual Bell Nozzle using Computational Fluid Dynamics", International Journal of Engineering Materials and Manufacture (2019) 4(1) 15-21.

7. Mehdi Nazarinia, Arash Naghib-Lahouti and Elhaum Tolouei, "Design and Numerical Analysis of Aerospike Nozzleswith Different Plug Shapes to Compare theirPerformance with a Conventional Nozzle", AIAC-11 Eleventh Australian International Aerospace Congress.

8. J. Mi - G. J. Nathan, "Statistical Properties of Turbulent Free Jets Issuing from Nine Differently-Shaped Nozzles", DOI 10.1007/s10494-009-9240-0.

9. Sreenath K R, Mubarak A K, "Design and analysis of contour bell nozzle and comparison with dual bell nozzle", IJRE| Vol. 03 No. $06 \mid$ June 2016

10. Summerfield, M., Foster, C., R., and Swan, W. C., "Flow Separation in Over- expanded Supersonic Exhaust Nozzles," Jet Propulsion, vol. 24, September-October 1954, pp. 319-321. 